\title{
Penerapan Model Pembelajaran Kooperatif Snowball Throwing dengan Discovery Learning Untuk Meningkatkan Keaktifan dan Prestasi
}

\author{
Nuha Puspaningtyas a,1, ${ }^{\text {a }}$, Krisdianto Hadiprasetyo a,2, Isna Farahsanti a,3 \\ a Pendidikan Matematika, Universitas Veteran Bangun Nusantara, Sukoharjo, Indonesia \\ ${ }^{1}$ puspaa.nuha@gmail.com*; ${ }^{2}$ krisdiyanto_presetyo@yahoo.co.id; ${ }^{3}$ isnafarahsanti@gmail.com \\ * Corresponding Author
}

Diterima 15 Juni 2020; Disetujui 21 Februari 2021; Diterbitkan 22 Februari 2021

\section{ABSTRACT}

The objectives of this study are to increase the activeness and students learning achievement through the Snowball Throwing type cooperative learning model with Discovery Learning. This research is a Classroom Action Research (CAR) which consists of 4 stages with 3 cycles. The subjects are 29 students of class VII B SMP Negeri 16 Surakarta for academic year 2019/2020. The data collection techniques in this study are test, observation, and documentation techniques. The data analysis technique is carried out by analyzing the observation sheet and the analysis of the success of the action. Based on the research, the percentage of pre-cycle activeness data is $33.38 \%$, the first cycle is $42.90 \%$, the second cycle is $52.40 \%$ and the third cycle is $71.50 \%$, while for classical completeness precycle learning achievement is obtained $20.69 \%$, cycle I $27.58 \%$, in cycle II it increased to $44.83 \%$ and cycle III increased to $75.86 \%$. From the results obtained, it can be concluded that the application of the Snowball Throwing type cooperative learning model with Discovery Learning can increase the activeness and students learning achievement of class VII B students of SMP Negeri 16 Surakarta in the academic year 2019/2020.
KEYWORDS

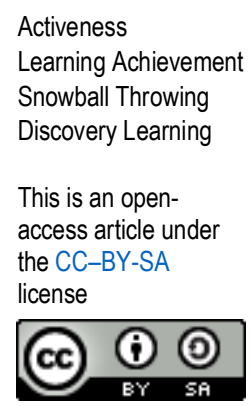

Activeness

Learning Achievement

Snowball Throwing

Discovery Learning

This is an openaccess article unde

license

\section{Pendahuluan}

Pendidikan merupakan suatu proses menanamkan dan mengembangkan pada diri seseorang berupa pengetahuan yang luas. Pendidikan ditanamkan mulai sejak dini agar anak bisa membiasakan diri dan mengembangkan pola pikir anak. Tidak hanya pendidikan formal yang diberikan tetapi pendidikan non formal pun tidak kalah penting untuk meningkatkan kreatifitas anak.

Matematika merupakan salah satu mata pelajaran yang diajarkan pada jenjang pendidikan dasar, pendidikan menengah maupun pendidikan tinggi. Banyak peserta didik di sekolah memandang matematika sebagai program studi yang paling sulit. Padalah matematika adalah mata pelajaran yang berguna dalam kehidupan sehari-hari dan merupakan salah satu mata pelajaran yang selalu di ujikan dalam Ujian Nasional. Oleh karena itu, matematika perlu diajarkan agar prestasi belajar matematika pada peserta didik di setiap jenjangnya dapat meningkat.

Untuk menentukan prestasi belajar matematika salah satunya ditentukan oleh metode pembelajaran yang digunakan oleh guru sangat berpengaruh terhadap cara belajar peserta didik. Penggunaan model dan metode pembelajaran yang tepat, kondisi kelas yang menyenangkan, sarana dan prasarana yang memadai serta penguasaan kompetensi yang dipelajari dapat membatu dan memudahkan peserta didik untuk memahami materi.

Menurut keterangan guru matematika kelas VII SMP Negeri 16 Surakarta, sebagian besar peserta didik masih mengalami kesulitan dalam menyelesaikan soal-soal matematika. Pembelajaran lebih cenderung menggunakan metode konvensional yakni ceramah dan pemberian tugas, hal tersebut menyebabkan peserta didik pasif dan merasa jenuh untuk mendengarkan penjelasan materi dari 
guru. Dalam kegiatan belajar mengajar (KBM), peserta didik masih malu dan tidak berani bertanya kepada guru jika mengalami kesulitan dalam memahami atau menyelesaikan soal sehingga mengakibatkan hasil belajar peserta didik yang kurang optimal.

Berdasarkan hasil wawancara dengan guru matematika dan pengamatan keaktifan peserta didik menggunakan lembar observasi serta pengamatan prestasi peserta didik menggunakan nilai UTS semester ganjil di seluruh kelas VII, hasil pengamatan yang diperoleh adalah keaktifan belajar dan prestasi belajar dan setiap kelas memiliki tingkat keaktifan dan rata-rata nilai yang berbeda beda. Kelas VII A memiliki tingkat persentase keaktifan 52,4\%, kelas VII B memiliki tingkat persentase keaktifan 33,38\%, kelas VII C memiliki tingkat persentase keaktifan 52,4\%, kelas VII D memiliki tingkat persentase keaktifan 47,5\%, kelas VII E memiliki persentase keaktifan 52,5\% dan kelas VII F memiliki tingkat persentase keaktifan 50\% . Tingkat prestasi belajar setiap kelas juga berbedabeda. Rata-rata nilai UTS kelas VII A 55,65, rata-rata nilai UTS kelas VII B 43,28, rata-rata nilai UTS kelas VII C 55,25, rata-rata UTS kelas VII D 50,38, dan rata-rata nilai UTS kelas VII E 46,10.

Dapat dilihat dari data diatas kelas B memiliki tingkat keaktifan yang rendah yaitu $40 \%$ dan memiliki tingkat prestasi yang rendah yaitu 45,05. Dari data obervasi yang telah dilakukan kelas B memiliki tingkat keaktifan dan prestasi yang rendah dimungkinkan karena model yang diberikan oleh guru kepada peserta didik hanya menggunakan model pembelajaran yang konvensional sehingga siswa kurang aktif dalam mengikuti kegiatan belajar mengajar dikarenakan model konvensional hanya berpusat kepada guru saja. Karena itu guru harus membuat suatu kegiatan belajar mengajar dengan model mengajar yang tepat dan efisien agar membuat siswa tertarik dalam menerima pelajaran sehingga materi pelajaran yang disampaikan membuat siswa merasa senang dan perlu untuk mempelajari materi pelajaran tersebut. Pemilihan model pembelajaran diharapkan akan meningkatkan keaktifan dan prestasi belajar siswa khususnya mata pelajaran matematika. Maka perlu adanya perbaikan dalam proses belajar mengajar di kelas $\mathrm{B}$, menggunakan model pembelajaran kooperatif. Model kooperatif merupakan cara agar dapat mengaktifkan siswa dalam pembelajaran di kelas. Karena model ini mengacu pada metode pembelajaran dimana siswa bekerja sama dalam kelompok kecil dan saling membantu dalam belajar. Pembelajaran kooperatif dapat membantu untuk meningkatkan pemahaman siswa dengan kemampuan akademik rendah maupun siswa dengan kemampuan akademik tinggi (Sudarsana 2018).

Ada berbagai tipe model pembelajaran kooperatif, salah satunya adalah snowball throwing. Menurut penelitian yang dilakukan oleh (Setiawan and Primawati 2019) menyimpulkan bahwa hasil belajar siswa yang dikenai model pembelajaran snowball throwing lebih baik daripada hasil belajar siswa yang dikenai pembelajaran konvensional. Penelitian lain oleh (Kuncoro and Purnami 2018) juga menyebutkan bahwa pembelajaran kooperatif snowball throwing lebih efektif daripada pembelajaran konvensional. Hal ini juga didukung oleh penelitian yang dilakukan (Styawan, Susilowati, and Wulandari 2019) yang menyatakan bahwa penerapan model pembelajaran kooperatif tipe snowball throwing memberikan pengaruh yang positif terhadap prestasi belajar siswa kelas VIII. Snowbal throwing juga dapat meningkatkan aktivitas belajar siswa sesuai dengan penelitian yang dilakukan oleh (Yoserizal and Rahmi 2019). Pembelajaran kooperatif tipe snowball throwing dilakukan dengan cara membagi siswa ke dalam beberapa kelompok secara heterogen dimana setiap kelompok membuat suatu pertanyaan yang dituliskan dalam selembar kertas kemudian digulung lalu dilemparkan kepada kelompok lain untuk dijawab (Simarmata 2018). Model pembelajaran ini juga memiliki kelebihan, dengan saling melempar kertas akan membuat siswa tertarik dan dapat meningkatkan aktivitas siswa dalam belajar (Styawan, Susilowati, and Wulandari 2019). Penerapan model pembelajaran snowbal throwing ini mengharuskan siswa untuk membuat pertanyaan, dimana bagian ini adalah hal yang penting ketika belajar, karena dapat menggali informasi, menginformasikan apa yang sudah diketahui, dan mengarahkan pada aspek yang belum diketahui (Asmarani 2017). Dalam penerapan model ini siswa akan bekerjasama, berbagi pendapat, melaksanakan tugsa masing-masing dengan penuh tanggung jawab, dan tentunya dapat menambah wawasan siswa (Munawaroh and Alamuddin 2014).

Pemilihan model pembelajaran yang tepat akan berdampak baik pada proses belajar mengajar di kelas sehingga dapat membuat siswa menjadi aktif dalam belajar yang tentunya juga berdampak baik pada prestasi belajar siswanya. Selain snowball throwing, model pembelajaran discovery 
learning juga dapat dijadikan alternatif untuk digunakan dalam pembelajaran, karena discovery learning adalah salah satu model pembelejaran yang berpusat pada siswa (student central learning) dan mengharuskan siswa aktif dalam pembelajaran (Maulida, Ningsih, and Bastian 2018). Penelitian terdahulu menyimpulkan bahwa model pembelajaran discovery learning lebih baik daripada model pembelajaran konvensional (Kadri and Rahmawati 2015). Hal ini juga sejalan dengan penelitian lain yang menyimpulkan bahwa ada pengaruh penggunaan model discovery learning terhadap hasil belajar matematika pada pokok bahasan Matriks (Fitriyah, Murtadlo, and Warti 2017). Untuk dapat aktif belajar dan berpikir maka siswa harus diberikan kebebasan untuk menggali pengalamannya sendiri agar dapat mengembangkan pengetahuannya dengan lebih mendalam. Siswa harus aktif dan mendominasi pembelajaran sehingga dapat mengembangkan potensi yang ada dalam dirinya (Supriyanto 2014).

Agar siswa aktif berpikir maka siswa harus diberi kesempatan untuk mencari pengalaman sendiri serta dapat mengembangkan seluruh aspek pribadinya. Siswapun harus lebih aktif dan mendominasi sehingga dapat mengembangkan potensi yang ada dalam dirinya. Dengan kata lain aktivitas siswa dalam pembelajaran bukan hanya mencatat dan mendengarkan penjelasan dari guru.

Pembelajaran yang baik tentunya harus dilakukan dengan menggunakan model pembelajaran yang sesuai agar tujuan pembelajaran dapat tercapai. Pembelajaran yang menyenangkan dan berpusat pada siswa dimana siswa diharuskan aktif dalam belajar akan membuat siswa menjadi lebih tertarik dalam belajar sehingga prestasi belajar menjadi lebih baik. Menggabungkan model pembelajaran kooperatif snowball throwing dengan discovery learning diharapkan dapat meningkatkan keaktifan dan prestasi belajar siswa.

\section{Metode}

Penelitian ini dilaksanakan di SMP Negeri 16 Surakarta pada awal bulan Januari 2020 sampai akhir Januari 2020. Metode penelitian yang digunakan adalah Penelitian Tindakan Kelas (PTK). Penelitian tindakan kelas adalah pendekatan untuk memperbaiki pendidikan melalui perubahan, dengan mendorong para guru untuk memikirkan praktik mengajar agar kritis terhadap praktik tersebut dan ada keinginan untuk mengubahnya. Penelitian tindakan kelas ini menggunakan penggabungan metode pembelajaran Snowball Throwing dengan metode pembelajaran Discovery Learning. PTK ini dilakukan dengan melalui suatu siklus. Setiap siklus melalui beberapa tahapan, yaitu plan, do, dan see. Siklus akan berulang jika indikator kinerja pada penelitian belum tercapai dan akan berhenti jika hasil yang diperoleh sudah sesuai dengan indikator kinerja (indikator ketercapaian). Indikator kinerja pada penelitian ini adalah, rerata prestasi belajar minimal 75 dengan siswa yang tuntas KKM minimal 70\% dan keatifan belajar siswa minimal $70 \%$.

\section{Hasil dan Pembahasan}

Berdasarkan hasil observasi awal dengan mewawancarai guru matematika diperoleh nilai Ulangan Akhir Semester (UAS) matematika diperoleh data yang ditampilkan pada Tabel 1. Dari hasil observasi awal tersebut masih banyak peserta didik yang mendapatkan nilai rendah dan dibawah KKM. Dari seluruh observasi yang dilakukan di kelas VII, kelas VII B adalah kelas yang tingkat Prestasinya paling rendah diantara kelas yang lain. Berdasarkan hasil observasi keaktifan kelas VII B pada Tabel 2. Kelas VIIB juga memiliki tingkat keaktifan yang lebih rendah dibandingkan dengan kelas VII yang lain.

Tabel 1. Observasi Prestasi Belajar Kelas VII B

\begin{tabular}{cc}
\hline Pencapaian & Pra Siklus \\
\hline Nilai Tertinggi & 85 \\
Nilai Terendah & 20 \\
Siswa Tuntas & 6 \\
Siswa Belum Tuntas & 23 \\
\hline Rata - rata & 43,28 \\
\hline Ketuntasan Klasikal & $20,69 \%$ \\
\hline
\end{tabular}


Tabel 2. Observasi Keaktifan Belajar Kelas VII B

\begin{tabular}{|c|c|c|c|c|c|}
\hline \multirow{2}{*}{ Indikator yang diamati } & \multicolumn{5}{|r|}{ Skor } \\
\hline & $\mathbf{0}$ & 1 & 2 & 3 & $\%$ keaktifan indikator ke-i \\
\hline Siswa aktif bertanya & & $\sqrt{ }$ & & & $33,4 \%$ \\
\hline Siswa aktif mengajukan pendapat & & $\sqrt{ }$ & & & $33,4 \%$ \\
\hline Siswa aktif mejawab pertanyaan & & & $\sqrt{ }$ & & $66,7 \%$ \\
\hline Siswa aktif berdiskusi & & $\sqrt{ }$ & & & $33,4 \%$ \\
\hline Siswa aktif memperhatikan penjelasan guru & & $\sqrt{ }$ & & & $33,4 \%$ \\
\hline Siswa aktif mengerjakan LKS & & $\sqrt{ }$ & & & $33,4 \%$ \\
\hline Siswa aktif berpartisipasi dalam permainan & $\sqrt{ }$ & & & & $0 \%$ \\
\hline Jumlah & 0 & 3 & 4 & 0 & $233,7 \%$ \\
\hline Persentase Keaktifan & & & & & $33,38 \%$ \\
\hline
\end{tabular}

Melihat data pra siklus tersebut, maka dari itu dilaksanakan siklus 1 untuk mengetahui tingkat keaktifan dan prestasi yang peserta didik kelas VII B melalui tes tertulis yang diujikan kepada peserta didik dan melakukan observasi keaktifan menggunakan lembar observasi keaktifan peserta didik. Sehingga mendapatkan hasil dari tes tertulis dengan rata-rata yang diperoleh adalah 51,72 dengan ketuntasan nilai 27,58\%. Hasil observasi keaktifan pada siklus 1 ditunjukkan pada Tabel 3.

Dari hasil siklus 1 masih banyak siswa yang nilainya kurang dan belum memenuhi ketuntasan minimal serta kurang aktif dalam mengikuti pembelajaran, maka perlu diadakannya kembali siklus 2. Dari siklus 2 diperoleh hasil tes tertulis yaitu 66,03 dengan ketuntasan nilai $44,83 \%$. Hasil observasi keaktifan pada siklus ke 2 ditunjukkan pada Tabel 4.

Sampai pada akhir siklus 2 ternyata masih banyak siswa yang nilainya kurang dan belum memenuhi ketuntasan minimal serta kurang aktif dalam mengikuti pembelajaran, maka perlu diadakannya kembali siklus 3. Dari siklus 3 diperoleh hasil tes tertulis 76,03 dengan ketuntasan nilai $75,86 \%$. Hasil observasi keaktifan pada siklus 3 disajikan pada Tabel 5. Untuk rangkuman peningkatan prestasi belajar siswa dapat dilihat pada Tabel 6.

Tabel 3. Hasil Observasi Keaktifan Siklus 1

\begin{tabular}{|c|c|c|c|c|c|}
\hline \multirow{2}{*}{ Indikator yang diamati } & \multicolumn{5}{|r|}{ Skor } \\
\hline & $\mathbf{0}$ & $\mathbf{1}$ & 2 & 3 & \% keaktifan indikator ke-i \\
\hline Siswa aktif bertanya & & $\sqrt{ }$ & & & $33,4 \%$ \\
\hline Siswa aktif mengajukan pendapat & & $\sqrt{ }$ & & & $33,4 \%$ \\
\hline Siswa aktif mejawab pertanyaan & & & $\sqrt{ }$ & & $66,7 \%$ \\
\hline Siswa aktif berdiskusi & & $\sqrt{ }$ & & & $33,4 \%$ \\
\hline Siswa aktif memperhatikan penjelasan guru & & & $\sqrt{ }$ & & $66,7 \%$ \\
\hline Siswa aktif mengerjakan LKS & & $\sqrt{ }$ & & & $34,4 \%$ \\
\hline Siswa aktif berpartisipasi dalam permainan & & $\sqrt{ }$ & & & $34,4 \%$ \\
\hline Jumlah & 0 & 5 & 2 & 0 & $300,4 \%$ \\
\hline Persentase Keaktifan & & & & & $42,9 \%$ \\
\hline
\end{tabular}

Tabel 4. Hasil Observasi Keaktifan Siklus 2

\begin{tabular}{|c|c|c|c|c|c|}
\hline \multirow{2}{*}{ Indikator yang diamati } & \multicolumn{5}{|r|}{ Skor } \\
\hline & $\mathbf{0}$ & 1 & 2 & 3 & \% keaktifan indikator ke-i \\
\hline Siswa aktif bertanya & & $\sqrt{ }$ & & & $33,4 \%$ \\
\hline Siswa aktif mengajukan pendapat & & $\sqrt{ }$ & & & $33,4 \%$ \\
\hline Siswa aktif mejawab pertanyaan & & & $\sqrt{ }$ & & $66,7 \%$ \\
\hline Siswa aktif berdiskusi & & & $\sqrt{ }$ & & $66,7 \%$ \\
\hline Siswa aktif memperhatikan penjelasan guru & & & $\sqrt{ }$ & & $66,7 \%$ \\
\hline Siswa aktif mengerjakan LKS & & $\sqrt{ }$ & & & $34,4 \%$ \\
\hline Siswa aktif berpartisipasi dalam permainan & & & $\sqrt{ }$ & & $66,7 \%$ \\
\hline Jumlah & 0 & 3 & 4 & 0 & $367 \%$ \\
\hline Persentase Keaktifan & & & & & $52,4 \%$ \\
\hline
\end{tabular}


Tabel 5. Hasil Observasi Keaktifan Siklus 3

\begin{tabular}{|c|c|c|c|c|c|}
\hline \multirow[b]{2}{*}{ Indikator yang diamati } & \multicolumn{5}{|c|}{ Skor } \\
\hline & $\mathbf{0}$ & 1 & 2 & 3 & $\begin{array}{l}\text { \% keaktifan } \\
\text { indikator ke-i }\end{array}$ \\
\hline Siswa aktif bertanya & & & $\sqrt{ }$ & & $66,7 \%$ \\
\hline Siswa aktif mengajukan pendapat & & & $\sqrt{ }$ & & $66,7 \%$ \\
\hline Siswa aktif mejawab pertanyaan & & & $\sqrt{ }$ & & $66,7 \%$ \\
\hline Siswa aktif berdiskusi & & & & $\sqrt{ }$ & $100 \%$ \\
\hline Siswa aktif memperhatikan penjelasan guru & & & $\sqrt{ }$ & & $66,7 \%$ \\
\hline Siswa aktif mengerjakan LKS & & & $\sqrt{ }$ & & $66,7 \%$ \\
\hline Siswa aktif berpartisipasi dalam permainan & & & $\sqrt{ }$ & & $66,7 \%$ \\
\hline Jumlah & 0 & 0 & 6 & 1 & $500,2 \%$ \\
\hline Persentase Keaktifan & & & & & $71,50 \%$ \\
\hline
\end{tabular}

Tabel 6. Prestasi Belajar Kelas VII B Siklus I, II, dan III

\begin{tabular}{cccc}
\hline Keterangan & Siklus I & Siklus II & Siklus III \\
\hline Nilai Rerata & 51,72 & 66,03 & 76,03 \\
Persentase Ketuntasan & $27,58 \%$ & $44,83 \%$ & $75,86 \%$ \\
\hline
\end{tabular}

Dari hasil siklus 3 tersebut, terdapat peningkatan jumlah peserta didik yang melampaui kriteria ketuntasan minimal dan terdapat peningkatan yang baik untuk keaktifan siswa yang dapat dilihat melalui lembar observasi keaktifan. Jadi, karena pencapaian nilai prestasi dan keaktifan sudah terpenuhi maka siklus penelitian ini berhenti di siklus 3. Dengan hal ini berarti model pembelajaran yang digunakan (snowball throwing dan discovery learning) berhasil untuk meningkatkan prestasi dan keaktifan peserta.

Dari hasil penelitian dapat diketahui bahwa model pembelajaran kooperatif snowball throwing dengan discovery learning dapat meningkatkan keaktifan dan prestasi belajar siswa. Hal ini sejalan dengan hasil penelitain penelitian yang menyatakan bahwa model discovery learning dapat meningkatkan keaktifan belajar siswa dalam pembejaran matematika pada jenjang SMP (Maulida, Ningsih, and Bastian 2018). Selain itu juga sejalan dengan penelitian lain menyimpulkan bahwa penerapan model pembelajaran kooperatif tipe snowball throwing dapat meningkatkan aktivitas dan prestasi belajar matematika siswa SMP (Hirzi, Sripatmi, and Hapipi 2015). Model pembelajaran kooperatif snowball throwing membuat siswa antusias dalam belajar karena dengan model discovery learning siswa berperan aktif dan kreatif untuk membuat pertanyaan ataupun menjawab pertanyaan dari siswa lain secara berkelompok. Permainan yang dilakukan dalam model ini juga dapat menumbahkan antusias siswa dan keaktifan siswa dalam belajar.

Model pembelajaran discovery learning juga dapat membantu meningkatkan keaktifan dan prestasi belajar siswa. Model ini memang mewajibkan siswa yang berperan aktif selama proses pembelajaran. Guru hanya bersifat sebagai fasilitator. Dengan demikian siswa tentu saja menjadi lebih bertanggungjawab dan aktif dalam belajar. Hal ini sesuai dengan hasil penelitian ini adalah yang terdahulu yang menyimpulkan ada pengaruh penggunaan model discovery learning terhadap hasil belajar matematika pada pokok bahasan Matriks (Fitriyah, Murtadlo, and Warti 2017). Selain itu juga sejalan dengan penelitian lain yang menyimpulkan bahwa model discovery learning dapat meningkatkan hasil belajar siswa (Rosarina, Sudin, and Sujana 2016). Juga senada dengan penelitian lain yang menyatakan bahwa pembelajaran menggunakan model discovery learning dapat meningkatkan hasil belajar siswa (Rosdiana, Boleng, and Susilo 2017).

Menggabungkan dua model pembelajaran, yaitu model pembelajaran kooperatif snowball throwing dengan discovery learning merupakan salah satu alternatif yang dapat digunakan untuk meningkatkan aktifitas mauoun prestasi belajar siswa, khususnya dalam pembelajaran matematika untuk SMP. Mengkombinasikan kedua model tersebut terbukti dapat menambah antusias siswa dalam belajar dengan pola bermain saling melempar gulungan kertas dan saling bertukar pertanyaan dan jawaban. Selain itu siswa juga dapat lebih bertanggungjawab dalam belajar karena semua 
terpusat pada siswa. Dengan demikian aktifitas maupun prestasi belajar siswa dapat menjadi lebih baik.

\section{Simpulan}

Dari hasil penelitian tindakan kelas yang telah dilakukan, maka dapat diambil simpulan bahwa melalui penerapan model pembelajaran kooperatif tipe snowball throwing dengan Discovery learning dapat meningkatkan keaktifan dan prestasi belajar matematika siswa kelas VII B SMP Negeri 16 Surakarta tahun pelajara 2019/2020.

\section{Referensi}

Asmarani, Dewi. 2017. "Pembelajaran Statistik Melalui Model Pembelajaran Kooperatif Tipe Snowball Throwing Untuk Meningkatkan Hasil Belajar Di Kelas VII SMP Negeri 1 Singosari." Al-Khwarizmi: Jurnal Pendidikan Matematika Dan Ilmu Pengetahuan Alam 5 (1): 55-64. https://doi.org/10.24256/jpmipa.v5i1.266.

Fitriyah, Ali Murtadlo, and Rini Warti. 2017. "Pengaruh Model Pembelajaran Discovery Learning Terhadap Hasil Belajar Matematika Siswa MAN Model Kota Jambi." Jurnal Pelangi 9 (2): 108-12. https://doi.org/10.22202/jp.2017.v9i2.1898.

Hirzi, Ristu Haiban, Sripatmi, and Hapipi. 2015. "Penerapan Model Pembelajaran Kooperatif Tipe Snowball Throwing Pada Pembelajaran Segiempat Untuk Meningkatkan Aktivitas Dan Prestasi Belajar Siswa SMPN 1 Lingsar Kelas VII-1 Tahun Pelajaran 2012/2013.” Jurnal Pijar MIPA 10 (1): 37-40.

Kadri, Muhammad, and Meika Rahmawati. 2015. "Pengaruh Model Pembelajaran Discovery Learning Terhadap Hasil Belajar Siswa Pada Materi Pokok Suhu Dan Kalor." Jurnal Ikatan Alumni Fisika Universitas Negeri Medan 1 (1): 29-33. https://doi.org/10.24114/jiaf.v1i1.2692.

Kuncoro, Beni Bayu, and Agustina Sri Purnami. 2018. "Efektivitas Model Pembelajaran Kooperatif Tipe Snowball Throwing Terhadap Prestasi Belajar Matematika Siswa Kelas XI IPS MA YAPPI Gubukrubuh GunungKidul.” Prosiding Seminar Nasional Etnomatnesia 6 (20): 1013-18. http://jurnal.ustjogja.ac.id/index.php/etnomatnesia/article/view/2454.

Maulida, Alfa Hida, Mitia Fatma Ningsih, and Titis Bastian. 2018. "Pengaruh Model Discovery Learning Terhadap Kemampuan Komunikasi Matematis Dan Keaktifan Belajar Siswa Smp." Delta: Jurnal Ilmiah Pendidikan Matematika 6 (1): 47-52. https://doi.org/10.31941/delta.v6i1.649.

Munawaroh, Mumun, and Ali Alamuddin. 2014. "Pengaruh Penerapan Model Pembelajaran Snowball Throwing Terhadap Hasil Belajar Matematika Siswa Dengan Pokok Bahasan Relasi Dan Fungsi." Eduma: Mathematics Education Learning and Teaching 3 (2): 163-73. https://doi.org/10.24235/eduma.v3i2.62.

Rosarina, Gina, Ali Sudin, and Atep Sujana. 2016. "Penerapan Model Discovery Learning Untuk Meningkatkan Hasil Belajar Siswa Kelas Ix Pada Pembelajaran Ipa." BIO EDUCATIO: (The Journal of Science and Biology Education) 1 (1): 372-80. https://doi.org/10.31949/be.v5i2.2597.

Rosdiana, D.T. Boleng, and Susilo. 2017. "Pengaruh Penggunaan Model Discovery Learning Terhadap Efektivitas Dan Hasil Belajar Siswa.” Jurnal Pendidikan: Teori, Penelitian, Dan Pengembangan 2(8) (2017): 1060-64. http://journal.um.ac.id/index.php/jptpp/. 
Setiawan, Erik, and Primawati. 2019. "Studi Perbandingan Model Pembelajaran Snowbal Throwing Dengan Pembelajaran Konvensional Terhadap Aktivitas Dan Hasil Belajar Dasar Perancangan Teknik Mesin (Dptm) Siswa Kelas X Jurusan Teknik Mesin Smk Negeri 1 Bukittinggi." Ranah Reasearch: Journal of Multidicsiplinary Research and Development 2 (1): 238-43. https://jurnal.ranahresearch.com/index.php/R2J/article/view/215.

Simarmata, Nada Naviana. 2018. "Upaya Meningkatan Hasil Belajar Siswa Dengan Menggunakan Model Pembelajaran Snowball Throwing." Jurnal Imiah Pendidikan Dan Pembelajaran 2 (1): 79-86. https://doi.org/10.23887/jipp.v2i1.13854.

Styawan, Sili Wijak, Dewi Susilowati, and Andhika Ayu Wulandari. 2019. "Pengaruh Model Pembelajaran Kooperatif Tipe Snowball Throwing Terhadap Prestasi Belajar Matematika." ABSIS: Mathematics Education Journal 1 (1). https://doi.org/10.32585/absis.v1i1.308.

Sudarsana, I Ketut. 2018. "Pengaruh Model Pembeajaran Kooperatif." Jurnal Penjaminan Mutu 4 (1): 20-31.

Supriyanto, Bambang. 2014. "Penerapan Discovery Learning Untuk Meningkatkan Hasil Belajar Siswa Kelas Vi B Mata Pelajaran Matematika Pokok Bahasan Keliling Dan Luas Lingkaran Di SDN Tanggul Wetan 02 Kecamatan Tanggul Kabupaten Jember.” Pancaran 3 (2): 165 74.

Yoserizal, and Ulfia Rahmi. 2019. "Perbedaan Aktivitas Belajar Siswa Antara Model Cooperative Learning Tipe Snowball Throwing Dengan Tipe Think Pair Share." Jurnal Basicedu 3 (4): 1055-64. 